\title{
Lise Öğrencilerinin Kariyer Kaygılarını Belirlemeye Yönelik Ölçek Geliştirme Çalışması
}

\section{Scale Development Study for Determining the Career Anxiety of High School Students}

\author{
Hicran ÇETİN GÜNDÜZ*, Funda NALBANTOĞLU YILMAZ**
}

Öz: Bu çalışmanın amacı lise eğitimine devam eden öğrencilerin mesleki gelişim süreçlerinde yaşadıkları kariyer kaygısını belirlemeye yönelik bir ölçek geliştirmektir. Araştırma 2014-2015 Eğitim-Öğretim yılında Nevşehir il merkezindeki 6 farklı lisede, 11 ve 12. sınıflarda okuyan öğrencilerden seçilen üç farklı çalışma grubu üzerinden yürütülmüş̧ür. Araştırmanın birinci çalışma grubu, 350 öğrenciden, ikinci çalışma grubu 337 öğrenciden, üçüncü çalışma grubu ise 687 öğrenciden oluşmaktadır. Ölçek geliştirme sürecinde açımlayıcı ve doğrulayıcı faktör analizleri kullanılmıştır. Kariyer kaygısı ölçeği iki boyutludur. Ölçeğin meslek seçimine yönelik kaygılarına ait güvenirliği .797 , aile etkisine yönelik kaygılarına ait güvenirliği ise .742 bulunmuştur. Ölçeğin iyilik uyum indeksleri; $\chi^{2} / \mathrm{sd}=2.518, \mathrm{RMSEA}=0.067, \mathrm{CFI}=0.95$, $\mathrm{NFI}=0.92, \mathrm{NNFI}=0.94, \mathrm{SRMR}=0.055, \mathrm{GFI}=0.92$ ve $\mathrm{AGFI}=0.90$ bulunmuştur.

Anahtar Kelimeler: Kariyer, kaygı, lise öğrencileri

\begin{abstract}
The purpose of this study is to develop a scale to determine the career anxiety of students attending the high school. The study was conducted during the 2014-2015 academic year on three different groups, the first of which was comprised of 350 grade 11 and 12 students from 6 different high schools located in Nevşehir city center, the second 337 and the third 687 students, respectively. In the scale development process, exploratory and confirmatory factor analysis was performed. According to EFA results, career anxiety scale has two factors. Cronbach alpha coefficient of anxiety over choice of profession was found to be .797 and that of family effect .742 in scope of career development. Fit indices, derived from confirmatory factor analysis (CFA) implemented in order to verify whether the model structure is plausible or not as a result of exploratory factor analysis, were found to be $\chi^{2} / \mathrm{sd}=2.518$, RMSEA $=0.067, \mathrm{CFI}=0.95, \mathrm{NFI}=0.92, \mathrm{NNFI}=0.94, \mathrm{SRMR}=0.055, \mathrm{GFI}=0.92$ and $\mathrm{AGFI}=0.90$.

Keywords: Career, anxiety, high school students
\end{abstract}

\section{Giriş}

Kariyer gelişimi çocukluk yıllarından itibaren başlayan, yaşam boyu devam eden karmaşık ve çok yönlü bir süreçtir (Gottfredson, 2002; Hartung, Porfeli ve Vondracek, 2005; Herr ve Cramer, 1992; Super, 1990). Pek çok araştırmacıya göre, kariyer gelişimi mesleki gelişim çizgisindeki ilerleme, duraklama ve gerilemeleri ifade eden, çocukluk yıllarından başlayarak emeklilik ve belki sonrasına da uzanabilen dinamik bir kavramdır (Akt. Ünsal, 2014).

Kariyer gelişimi sürecinde Super'a göre 15-24 yaşları arasında bireyler çevresini, rolleri ve etkinlikleri keşfetmektedir (Ritter vd., 2014). Ginzberg'de benzer şekilde ergenlik yıllarına denk gelen bu dönemde mesleki kararlarda ilgi, yetenek ve değerlerin düşünülmeye başladığını belirtmektedir (Muro ve Kottman, 1995). Lise yılları, ergenin işe ya da üniversite eğitimine geçişinde kritik yıllardır ve bu hazırlanma süreci kariyer hakkında seçim yapmayı içermektedir (Rowland, 2004). Super'a göre kariyer araştırmaları ve karar verme ergenlik dönemi boyunca kariyer gelişiminde merkezi bir role sahiptir (Brown, 1997).

Gençlerin çoğu, temel eğitimi ya da liseyi bitirip, meslek seçme konusunda kesin bir karar verme durumunda kaldıkları zaman şaşkınlığa düşmekte ve bütün hayatlarını geçirecekleri uğraşı alanlarının seçimlerini tesadüfe bırakmaktadırlar (Kuzgun, 2011). Türkiye'deki meslek seçimiyle ilgili kararlar hemen hemen geri dönülmezdir. Öğrencilerin mesleki yönlendirme ile yönetmeliklere göre, en azından yönelecekleri lise türlerini sekizinci ya da dokuzuncu sınıftan

*Yrd.Doç.Dr., Başkent Üniversitesi, Eğitim Fakültesi, Ankara-Türkiye, e-posta: hicrancetin@ gmail.com

**Yrd.Doç.Dr., Nevşehir Hacı Bektaş Veli Üniversitesi, Eğitim Fakültesi, Nevşehir-Tütkiye, e-posta: fundan@nevsehir.edu.tr 
sonra seçmeleri gerekmektedir. Merkezi bir giriş sınavına göre öğrenciler, üniversitelerdeki programlara yerleştirildikten sonra, bu programdan vazgeçip başka bir programa geçmek için yeniden bu sınavlara katılmak zorundadırlar (Özyürek, 2013).

Kariyer gelişimi sürecinde öğrenciler mesleki yönelimlerini belirlemek ve buna uygun eğitimi alabilmek için uğraşırken, sık sık değişen eğitim sistemi, müfredat programları, merkezi giriş sınavında yapılan değişiklikler ve uzun vadede işsizlik sorunu gibi sorunlar öğrencilerin karar verme süreçlerinde etkili olmaktadır. İlgi, yetenek ve kişisel özelliklere göre karar verme isteği, akademik başarı, aile beklentileri, mesleğin toplumdaki saygınlığı ve iş bulabilme imkânları arasında öğrenciler kimi zaman sıkışıp kalmakta ve gerçekte istedikleri ya da yapabilecekleri alanların dişına yönelmektedirler. Bununla birlikte henüz mesleki geleceğine ilişkin hayaller kurma ve idealler oluşturma evresinde iken verilen kararların geri dönülmezliği de öğrenciler üzerinde olumsuz duygulara yol açabilmektedir. Vignoli, Croity-Belz, Chapeland, Fillipis ve Garcia'nın da (2005) belirttiği gibi, öğrencilerin yaşadıkları kaygı durumları kariyer gelişimlerini etkileyen faktörlerden bir tanesidir.

Mallet (2002) tarafindan, mesleki bağlamda kaygının yaşanması sosyal kaygı olarak tanımlanmaktadır. Çünkü toplum içerisinde, çalışan ya da öğrenci olarak kişinin pozisyonuna ilişkin endişelerini içermektedir. Ergenlerde kariyer kaygısı, sürekli kayg1 olarak giderek artmaktadır (Akt., Vignoli, Croity-Belz, Chapeland, Fillipis ve Garcia, 2005). Mallet ve Vignoli (2005) tarafından sürekli kariyer kaygısının (career trait anxiety), kişinin akademik ve profesyonel kariyerine ilişkin kaygılar, kariyer gelişimi sürecindeki kararlarda aileyi hayal kırıklığına uğratma korkusu, iş ya da akademik bir gereksinimden dolayı aileden ve yakın arkadaşlardan uzaklaşma korkusu olarak üç farklı biçimi tanımlanmıştır (Akt., Vignoli vd., 2005; Vignoli, 2015). Diğer taraftan Blustein ve Phillips (1988), geç ergenlik döneminde durumluk kaygının, kariyer araştırması üzerine etkilerini incelemiştir. Bu araştırmalara rağmen, bir kişilik özelliği olarak kaygı, kariyer gelişimi sürecinde tam anlamıyla incelenmemiştir (Akt. Vignoli vd., 2005).

Literatürde kariyer gelişimi sürecinde kaygı ile ilişkili olarak yapılan çalışmalara bakıldığında, çalışmaların özellikle kariyer kararsızlığı (career indesicion) ve kaygı arasındaki ilişkiye odaklandığı görülmektedir (Campagna ve Curtis, 2007; Daniels, Stewart, Stupnisky, Perry ve LoVerso, 2011; Fuqua, Newman ve Seaworth; 1988; Fuqua, Seaworth ve Newman, 1987; Hawkins, Bradley ve White, 1977; Peng, 2005). Örneğin; Mojgan, Kadir ve Soheil (2011), İranlı lisans öğrencileri ile yaptığı çalışmalarında sürekli kaygının kariyer kararsızlığında durumluk kaygıdan daha fazla etkiye sahip olduğunu, kaygı ve kariyer kararsızlığ 1 arasındaki ilişkinin pozitif yönde olduğunu bulmuşlardır. Campagna ve Curtis (2007) ise sürekli ve durumluk kaygının kariyer karasızlığı üzerinde bağımsız bir etkiye sahip olduğunu belirtmiş ve durumluk kaygının kariyer netliğinde (career certainity) daha güçlü bir belirleyici olduğunu ortaya koymuşlardır. Corkin, Arbona, Coleman ve Ramirez (2008), üniversite öğrencileri ile yürüttüğü çalışmada kariyer karasızlığı ile kaygı arasındaki pozitif ilişkiye dikkat çekerken, Hartma, Fuqua ve Blum (1985), kariyer kararsızlığına ilişkin kurduğu path modelinde sürekli kaygının kariyer karasızlığı ile ilişkisini vurgulamıştır. Başka bir çalışmada ise, Peng (2005), Vignoli ve diğerleri (2005) kariyer araştırma davranışlarının kaygı ile ilişkisini ortaya koyarken, Vignoli (2015) ergenlerin kariyer karsızlıkları ve kariyer araştırmalarının (career exploration) genel sürekli kaygı ve kariyer kaygısı ile ilişkili olduğunu belirtmiş̧tir. Aynı zamanda genel sürekli kaygı ve kariyer kaygısı, kariyer karasızlıkları ve kariyer araştırmalarının arasındaki ilişkide aracılık etmektedir. Sürekli kaygının kariyer karasızlıklarında öncelikli belirleyici olduğu çalışmalar da bulunmaktadır (O'Hare ve Tamburri, 1986).

Türkiye'de ergenlik döneminde kariyer kaygısına yönelik çalışmalara bakıldığında, bu konu üzerine yapılmış bir çalışma bulunamamıştır. Lise düzeyinde kariyer gelişimi daha çok üniversite sınavları ile ilişkilendirilmiştir (Alkan, 2014; Özdemir Yaylacı, 2007). Diğer taftan kaygı ve kariyer gelişimi üzerine yapılmış sınırlı sayıda çalışma bulunduğu görülmektedir (Işık, 2012; Işık, 2014). Çocukluk döneminde kariyer gelişimi ile durumluk kaygı ilişkisini inceleyen Işı1k (2014), çocuk kariyer gelişimi ile durumluk kaygı arasında negatif ilişki bulurken, yine Işık 
(2012), üniversite öğrencilerinin kariyer kararı yetkinlik beklentisi yükseldikçe sürekli kayg1 düzeyleri ve olumsuz duygularının azaldığını belirtmiştir. Lise öğrencileri ile yürütülen çalışmalarda kaygı ile ilişkisi bulunan kariyer karasızlığı üzerine yapılmış çalışmalar da göze çarpmaktadır (Bacanlı, Eşici ve Özünlü, 2013). Ancak bu çalışmalarda kariyer karasızlıkları ve kaygı ilişkisine değinilmemiştir.

Literatürde kariyer gelişimi ve kaygıya ilişkin çalışmalarda kaygının çoğunlukla genel ve sürekli kayg1 ölçekleri ile ölçüldügüü görülürken (Campagna ve Curtis, 2007; Hardin, Varghese, Tran ve Carlson, 2006; Mojgan vd., 2011; Peng, 2005), kariyer kaygisının Vignoli ve diğerleri, (2005) ve Vignoli, (2015) tarafından "Gelecek Okul ve Kariyer Kaygısı" (Future School and Career Anxiety) ölçeği kullanılarak belirlendiği görülmektedir.

Türkiye'de yapılan çalışmalarda da lise yıllarında kariyer kaygısını ölçen çalışmalara rastlanmamış olmakla birlikte, üniversite öğrencilerine yönelik "Kariyer Uyum Yeteneği Ölçeği" (Kanten, 2012), "Kariyer Uyumu ve İyimserliği Ölçeği” (Erdoğmuş Zorver ve Korkut Owen, 2014), "Kariyer Karar Ölçeğii" (Büyükgöze-Kavas, 2012), "Kariyer Geleceği Ölçeği" (Kalafat, 2012), lise öğrencilerine yönelik "Duygusal ve Kişilik İlişkili Kariyer Karar Verme Güçlükleri Ölçeği” (Öztemel, 2014) göze çarpmaktadır. Bu ölçme araçları ise daha çok kariyer karasızlıklarını belirlemeye yöneliktir.

Özet olarak; lise yılları ergenler için kariyer gelişimi açısından önemli kararlar aldıkları yıllardır. $\mathrm{Bu}$ yıllarda ergenlerin yaşadıkları kariyer kaygısının belirlenebilmesi önemli görülmektedir. Türkçe literatürde ergenlik döneminde kariyer kaygısını ölçmeye yönelik bir ölçme aracına rastlanmamıştır. Bu alanda kullanılacak bir ölçeğin literatüre kazandırılması önemli görülmektedir. Geliştirilen bu ölçeğin lise öğrencilerinin kariyer kaygılarını belirlemede faydalı olacağı düşünülmektedir.

\section{Yöntem}

Araştırma lise öğrencilerinin kariyer kaygılarını belirlemeye yönelik bir ölçek geliştirme çalışmasıdır. $\mathrm{Bu}$ doğrultuda kariyer kaygısı ölçeğini geliştirme sürecine yönelik izlenen aşamalar aşağıda sunulmuştur.

\section{Çalışma Grubu ve İşlem}

Araştırma 2014-2015 Eğitim-Öğretim yılında üç farklı çalışma grubu üzerinden yürütülmüştür. Araştırmada geliştirilen ölçeğin faktör yapısını belirlemek amacıyla yapılan Açımlayıcı Faktör Analizi (AFA) birinci çalışma grubu üzerinden, çıkan yapının, bir model olarak doğrulanıp doğrulanmadığının sınanması için kullanılan Doğrulayıcı Faktör Analizi (DFA) ikinci çalışma grubu üzerinden yapılmıştır. Ölçeğin güvenirliği, ölçeğin maddelerine ilişkin düzeltilmiş madde-toplam puan korelasyonları ve \%27'lik alt-üst grup madde ortalama puanları arasındaki fark ise birinci ve ikinci çalışma gruplarının birleştirilmesiyle oluşturulan üçüncü çalışma grubundan elde edilmiştir.

Araştırmanın birinci çalışma grubunu, Nevşehir il merkezindeki 6 farklı lisenin 11 ve 12. sınıflarında okuyan 350 öğrenci oluşturmaktadır. Araştırmaya katılan öğrencilerin \%31.4’ü $(n=110)$ 11. sinıf, \%68.6'sı ( $n=240)$ 12. sınıf öğrencisidir. Ayrıca öğrencilerin \%66.3'ü $(n=232)$ kız, \%33.7'si ise $(\mathrm{n}=118)$ erkektir. Araştırmanın ikinci çalışma grubunu, Nevşehir il merkezindeki 6 farklı lisenin 11 ve 12. sınıflarında okuyan 337 öğrenci oluşturmaktadır. Araştırmaya katılan öğrencilerin \%68.8'i $(\mathrm{n}=232)$ 11. sınıf, \%31.2'si $(\mathrm{n}=105)$ 12. sınıf öğrencisidir. Öğrencilerin \%52.8'i $(\mathrm{n}=178) \mathrm{k} 1 \mathrm{z}, \% 47.2$ 'si ise $(\mathrm{n}=159)$ erkektir. Araştırmanın üçüncü çalışma grubu ise 687 öğrenciden oluşmaktadır. Araştırmaya katılan öğrencilerin $\% 49.8$ 'i (n=342) 11. sinıf, \%50.2'si (n=345) 12. sinıf öğrencisi, \%59.7'si $(n=410)$ kız, \%40.3’ü ise $(n=277)$ erkektir.

\section{Ölçeğin geliş̧tirilmesi}

Ölçek geliştirme sürecinde ilk olarak kaygı, kariyer gelişimi ve kariyer kaygısı ile ilgili literatür taraması (Kanten, 2012; Saban, Korkmaz ve Akbaşl1, 2004; Patton ve McMahon, 2014; Spielberger, 1972; Strongman, 1995; Varol, 1990; Vignoli vd., 2005; Vignoli, 2015; Ulu, 2007) 
yapılmış, kariyer kaygısına ilişkin göstergelerin neler olabileceği ve konuyla ilgili hali hazırda ölçek olup olmadığı araştırılmıştır. Yapılan literatür taramasından Türkçe konuyla birebir ilgili bir ölçeğe rastlanmamakla birlikte farklı konularda (araştırma kaygısı, okuma kaygısı, istatistik kaygısı, bilgisayar kullanımına ilişkin kaygı, sosyal kaygı, sosyal görünüş kaygısı, dil öğrenimine ilişkin kaygı vb.) yapılan kayg1 ölçekleri ile bir mesleğe yönelik hazırlanan mesleki kayg1 ölçeklerine rastlanmıştır (Akgün ve Özgür, 2014; Cabı ve Yalçınalp, 2013; Ceyhan ve Gürcan-Namlu, 2000; Doğan, 2010; Ergür-Oktar, 2004; Köklü, 1996; Köse, 2006; Melanlığlu, 2014; Öner ve Le Compte, 1998; Özbay ve Palanc1, 2001; Öztürk, 2013; Saban, Korkmaz ve Akbaş11, 2004; Ünaldı ve Alaz, 2008). Kaygı ve kariyer kaygısına ilişkin yapılan literatür taraması ve farklı konularda hazırlanmış kaygı ölçekleri incelenmiş ve maddelerin oluşturulmasında ifadeler dikkate alınmıştır.

Hedef gruba benzer bir grupta konu ile ilgili kompozisyon yazdırılmıştır. 12. sınıftan 25 öğrenci, 11. sınıftan 25 öğrenci olmak üzere toplam 50 öğrenciye kariyer gelişiminde yaşanan kaygı/endişelerine ait dört adet açık uçlu soru yöneltilmiş ve bu sorulara verilen cevaplarını da içeren bir kompozisyon yazmaları istenmiştir. Öğrencilere konuyla ilgili yöneltilen sorular, kariyer gelişimlerine/seçimlerine/planlarına yönelik aileden ve eğitim sisteminden kaynaklı endişe-kaygıları, kariyer gelişimlerine yönelik yaşadıkları genel kaygılar ile bir mesleğe yönelme, ilgili alanda eğitim alma, iş bulma gibi konulardaki kaygılarını içermektedir.

Yapılan alınyazın çalışmaları ve kompozisyon verilerinden hareketle taslak ölçek maddeleri yazılmıştır. Hazırlanan taslak ölçek maddeleri ölçme ve değerlendirme alanından iki, psikolojik danışma ve rehberlik alanından iki ve lisede rehber öğretmenlik yapan iki olmak üzere toplamda altı uzmana sunularak görüş alınmıştır. Uzman görüşleri için bir form hazırlanmıştır. Bu forma göre uzmanlardan hazırlanan ölçek maddelerinin "kariyer kaygısını ölçme amacına uygunluk" ve "hedef kitle tarafından anlaşılırlık" açılarından değerlendirmeleri, eklemek istedikleri madde varsa eklemeleri istenmiştir. Uzmanların kariyer kaygısını ölçme amacına uygunluk ve hedef kitle tarafindan anlaşılırlık açılarından görüşleri her madde için "uygun", "uygun değil" seçeneklerinden birini işaretlemeleri ve uygun değilse gerekçesini açıklamaları şeklinde alınmıştır. Her bir ölçek maddesi için alınan uzman görüşleri incelenmiş ve uyuşma düzeyleri belirlenmiş̧tir. Uyuşma düzeyi \%90'nın altında olan maddeler ölçek formundan çıkartılmıştır (Büyüköztürk, 2007). Alınan uzman görüşleri doğrultusunda bazı madde ifadelerinde düzeltmeler yapılmış, bazı maddeler ise çıkartılmıştır. Son aşamada 35 maddeden oluşan taslak bir ölçek oluşturulmuştur. Hazırlanan son ölçek maddeleri dilin kullanımı açısından 1 Türk Dili uzmanına gösterilmiştir. İlgili uzmanın anlaşılırlık, yazım kuralları ve noktalama işaretlerinin kullanımı ile ilgili görüşleri doğrultusunda, ölçek maddeleri tekrar gözden geçirilmiştir. Ölçek maddeleri "hiç katılmıyorum (1)", "katılmıyorum (2)", "kararsızım (3)", "katıliyorum (4)" ve "tamamen katıllyorum (5)" şeklinde 5'liLikert tipinde hazırlanmıştır.

\section{Verilerin analizi}

Hazırlanan ölçek uygulandıktan sonra tam doldurulmayan ve istekli doldurulmadığı anlaşılan formlar çalışma gruplarına dâhil edilmemiştir. Her bir çalışma grubuna ait verilerde uç, sapan, kayıp ve hatalı değerler olup olmadığı ile maddelere ait çarpıklık-basıklık katsayıları ve madde çiftleri arasındaki korelasyon incelenmiştir. Madde puanlarının normal dağılım gösterdiği ve madde çiftleri arasında çoklu ve tekli bağlantı olmadığı belirlenmiştir. Bu doğrultusunda ölçeğin geçerlik ve güvenirlik çalışmaları yapılmıştır.

Uygulanan ölçeğin faktör yapısını belirlemek amacıyla birinci çalışma grubunda Açımlayıcı Faktör Analizi (AFA), çıkan yapının bir model olarak doğruluğunun sınanması için ise ikinci çalışma grubunda Doğrulayıcı Faktör Analizi (DFA) yapılmıştır.

Açımlayıcı Faktör Analizi yapmadan önce verilerin bu analize uygun olup olmadığ değerlendirilmiştir. İlk olarak analiz için gerekli olan katılımcı sayısı değerlendirilmiştir. Literatürde açımlayıcı faktör analizi yapabilmek için gerekli olan katılımcı sayısının genel olarak ölçekteki madde sayısının 5-10 katı kadar olması gerektiği belirtilmektedir (Bryman ve Cramer, 2001; Child, 2006; Pett, Lackey ve Sullivan, 2003; Tavşancıl, 2006). Ayrica Comrey 
ve Lee (1992), faktör analizinde 100 katılımcıyı zayıf, 200'ü orta, 300'ü iyi, 500'ü çok iyi ve 1000 katılımciyı mükemmel olarak ifade etmektedir (Akt. Tabachnick ve Fidell, 2001). Bu açıdan açımlayıcı faktör analizinin yapıldığı birinci çalışma grubundaki katılımcı sayısının faktör analizi için yeterli olduğu söylenebilir.

Verilerin faktör analizine uygunluğu ikinci olarak Kaiser-MayerOlkin (KMO) katsayısı ve Bartlett Sphericity (küresellik) Testi ile değerlendirilmiştir. KMO değeri için 1'e yaklaştıkça çok mükemmel, 0.90 'larda mükemmel, 0.80 'lerde çok iyi, 0.70 ve 0.60 'larda zayıf, 0.50 'nin altında ise faktör analizine devam edilemeyeceği yorumu yapılmaktadır (Çokluk, Şekercioğlu ve Büyüköztürk, 2010; Tavşanc1l, 2006). KMO değerinin 0.60'dan yüksek, Bartlett küresellik testinin ise anlamlı çıkması verilerin faktör analizine uygun olduğunun, verinin çok değişkenli normal dağılıma sahip olduğunun da bir göstergesidir (Büyüköztürk, 2007; Tavşanc1l, 2006).

Faktör analizinde birçok faktörleştirme ve döndürme tekniği vardır. Ölçek geliştirme sürecinde en yaygın olarak tercih edilen faktörleştirme tekniği temel bileşenler analizidir (Büyüköztürk, 2007; Şencan, 2005). Faktör analizinde iki tür döndürme yapılabilir. Dik döndürme teknikleri faktörler arası ilişki olmadığı düşünüldüğünde kullanılmaktadır. Dik döndürme tekniklerinden ise en sık kullanılan varimax ve quartimaxdır (Büyüköztürk, 2007). Dik döndürme tekniklerinin yanı sıra direct oblimin, quartimin, promax gibi eğik döndürme teknikleri de vardır. Eğik döndürme faktörler arasında ilişki olduğu düşünüldügünde kullanılmaktadır. Ölçek geliştirme sürecinde söz konusu psikolojik değişkenler olduğunda, deneysel olarak dik ve eğik döndürme denenerek ortaya çıkan yapının kavramsal yapı ile örtüşmesi ayrı ayrı incelenmelidir (Erkuş, 2012). Çünkü psikolojik özelliklerin büyük bir kısmı çok boyutludur ve bu boyutların bazıları birbiriyle ilişkili bazıları ilişkisiz olabilir (Erkuş, 2012). $\mathrm{Bu}$ nedenle çalışma kapsamında varimax ve direct oblimin (delta açısı=0) kullanılarak açımlayıcı faktör analizi yapılmış ve çıkan sonuçlar kavramsal yapı çerçevesinde incelenmiştir. Her iki döndürme tekniği uygulanarak yapılan analizlerde KMO, Barlett testi sonuçları, açılanan toplam varyans, maddelerin ortak varyansı ve her bir faktörde yer alan maddeler değişmemiştir. Bununla birlikte Tabachnick ve Fidell (2001), iyi bir veri setinde döndürme tekniklerinin benzer sonuçlar verdiğini belirtmiştir. Farklı döndürme tekniklerine göre elde edilen sonuçlar da bu görüşü destekler niteliktedir. Bu doğrultuda, yapılan açımlayıcı faktör analizinde faktörleştirme tekniği olarak temel bileşenler analizi, döndürme tekniği olarak da direct oblimin bulguları raporlanmıştır. Maddelerin ölçekte kalıp kalmamasına karar vermede ise faktör yük değerinin alt sınırı olarak 0.32 benimsenmiştir (Tabachnick ve Fidell, 2001).

Açımlayıcı faktör analizinden elde edilen yapının bir model olarak doğruluğu için ise ikinci çalışma grubu üzerinde doğrulayıcı faktör analizi yapılmıştır. Kariyer Kaygısı Ölçeği'nin DFA sonucu ise, $\chi^{2} /$ sd oran1, RMSEA, CFI, NFI, NNFI, SRMR, GFI ve AGFI uyum indeksleri dikkate alınarak değerlendirilmiştir. Kariyer Kaygısı Ölçeğinin güvenirliği üçüncü çalışma grubu üzerinden Cronbach Alfa iç tutarlılık katsayısı ile belirlenmiştir. Madde geçerliğine kanıt sağlamak için ölçekte yer alan her bir madde için madde-toplam puan korelasyonu hesaplanmış, $\% 27$ 'lik alt ve üst grup madde ortalama puanları ilişkisiz t testi ile incelenmiştir. Tüm bu analizler için ise SPSS 15 (2006) ve LISREL 8.7 (Jöreskog ve Sörbom, 2004) programları kullanılmıştır.

\section{Bulgular}

\section{Açımlayıcı faktör analizine ilişkin bulgular}

Birinci çalışma grubu ile yapılan açımlayıcı faktör analizinden elde edilen KMO değeri 0.814 bulunmuştur. Bu doğrultuda örneklem büyüklügünün faktör analizi yapmak için çok iyi olduğu sonucuna ulaşılmıştır. Bartlett küresellik testi sonuçları incelendiğinde ise elde edilen ki-kare değerinin manidar olduğu $\left(\chi^{2}=2939.388, \mathrm{p}<0.01\right)$ belirlenmiştir. $\mathrm{Bu}$ doğrultuda verinin çok değişkenli normal dağılımdan geldiği kabul edilmiştir. Bu bulgular çerçevesinde verinin faktör analizi yapmak için uygun olduğu söylenebilir.

Faktörleştirme tekniği olarak temel bileşenler analizi, döndürme tekniği olarak da direct oblimin kullanılarak açımlayıcı faktör analizi yapılmıştır. Yapılan ilk analizde öz değeri 1'in 
üzerinde olan 9 faktör belirlenmiştir. Belirlenen faktörlerin toplam varyansın \% 53.762'sini açıkladığ1 görülmüştür. Her bir faktörün toplam varyansa yaptı̆̆1 katk1 incelendiğinde 3 faktörden sonra katkı azalmaktadır. Maddelere ait faktör yükleri incelendiğinde, 0.32 'nin altında olan 10 madde ve birden fazla faktörde yük veren (faktör yükleri arasındaki fark .10'dan düşük olan) 11 madde olduğu belirlenmiştir. $\mathrm{Bu}$ maddeler sırasıyla analiz dişı tutularak AFA tekrarlanmıştır. Madde atımında her atılan maddenin anlamlı yapıyı bozmamasına dikkat edilmiştir. Ayrıca her madde atımından önce madde toplam ölçek korelasyonları incelenmiş ve atılan maddelerin birçoğunun madde toplam ölçek korelasyonlarının 0.20 altında olduğu belirlenmiştir.

Kalan maddeler ile faktör analizi tekrarlandığında KMO değeri 0.856 bulunmuş, Bartlett küresellik testi sonuçları ise verinin faktör analizi yapmaya uygun olduğunu $\left(\chi^{2}=1264.615, \mathrm{p}<0.01\right)$ göstermiştir. Yapılan açımlayıcı faktör analizi sonucunda toplam varyansın \%44.4'lük kısmını açıklayan iki faktörlü bir yapı elde edilmiştir. Şekil 1'de verilen özdeğerler grafiği de iki faktörü destekler niteliktedir.

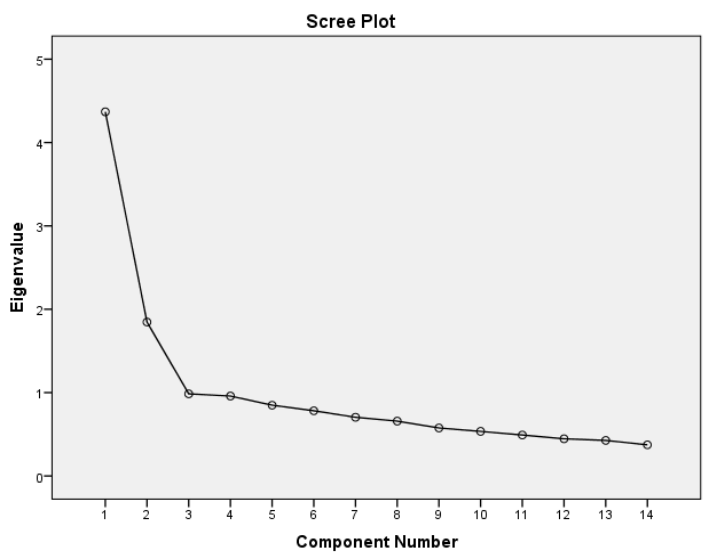

Şekil 1. Özdĕgerler Grafiği

AFA sonuçlarına ilişkin bulgular ise Tablo 1'de sunulmuştur. Tablo 1'de verildiği gibi meslek seçimine yönelik boyut 9 maddeden oluşmakta ve toplam varyansın \%24.67'sini açıklamaktadır. Meslek seçimine yönelik boyutta bulunan maddelerin faktör yükleri .740 ile .502 arasında değişmektedir. Aile etkisine yönelik boyut ise 5 madden oluşmakta ve toplam varyansın \%19.72'sini açıklamaktadır. Aile etkisine yönelik boyutta bulunan maddelerin faktör yükleri .824 ile .561 arasında değişmektedir. Ölçeğin açıkladığ 1 toplam varyans ise \%44.4'dür. Sosyal bilimlerde açıklanan toplam varyansın \%40 ile \%60 arasında olması yeterli olarak görülmektedir (Akt. Tavşanc1l, 2006).

Tablo 1. Döndürme Sonrası Açımlayıcı Faktör Analizi Sonuçları

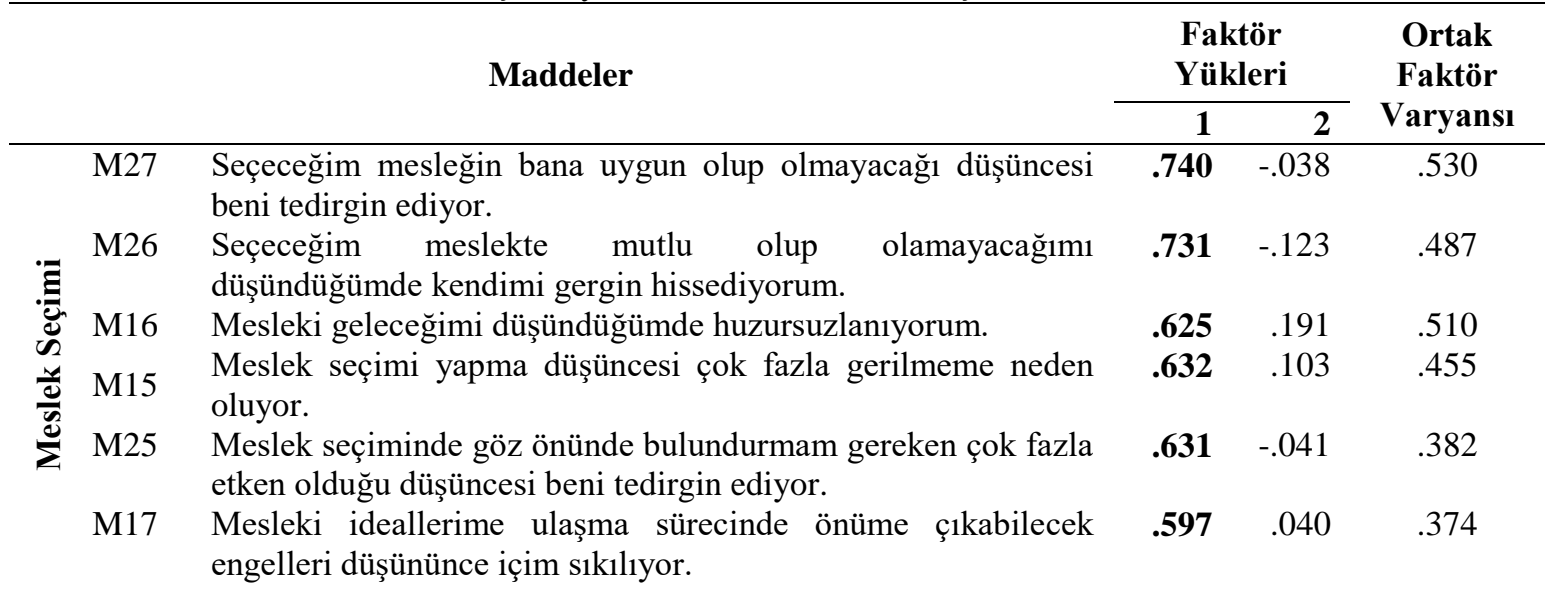




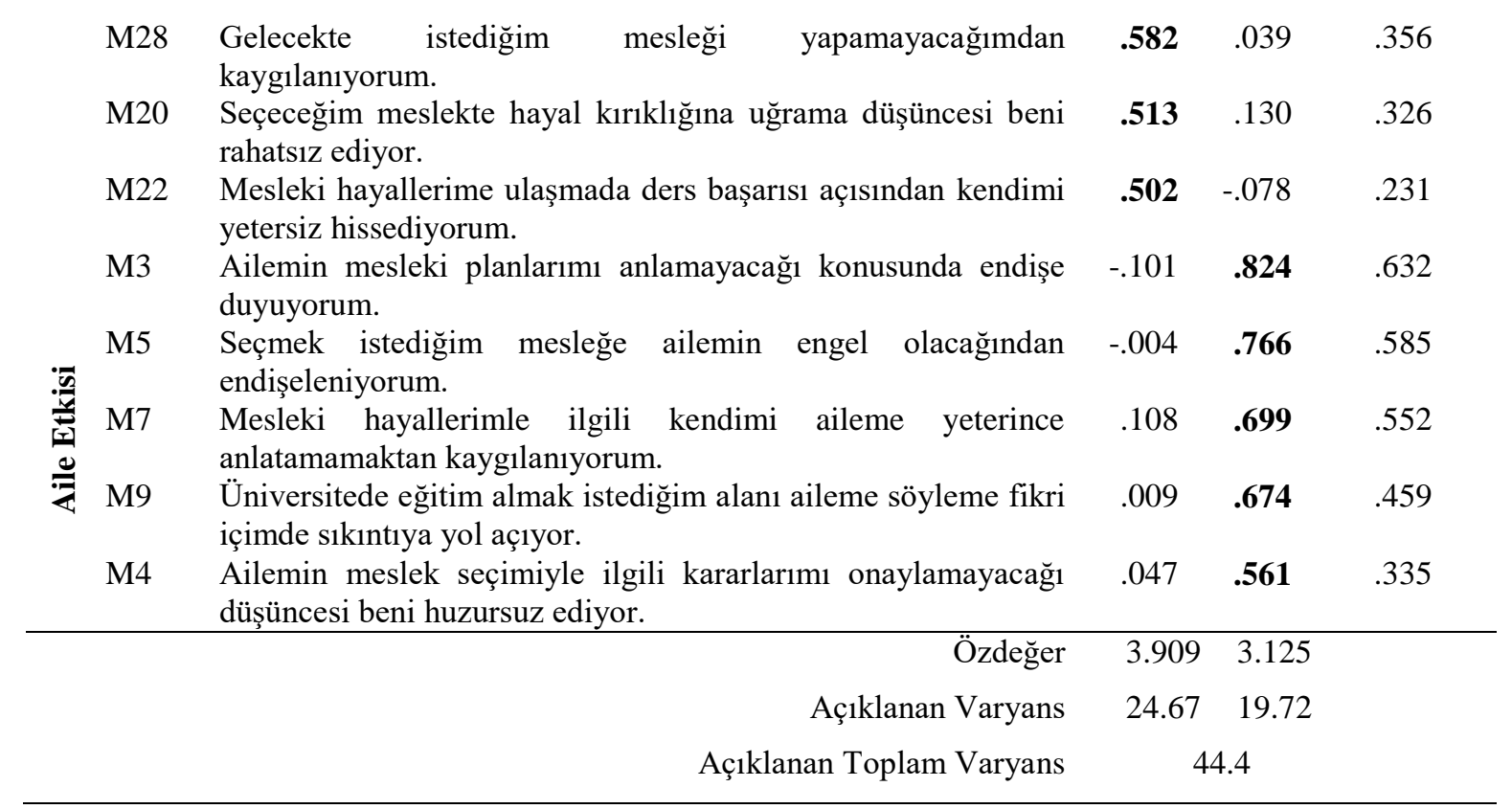

AFA sonuçlarına göre maddeler ve kuramsal yapı dikkate alınarak lise öğrencilerinin kariyer kaygılarını ölçmek amaçlı geliştirilen ölçeğin birinci faktörü meslek seçimine yönelik kaygı, ikinci faktör ise aile etkisine yönelik kaygı olarak adlandırılmıştır.

Ölçeğin, açımlayıcı faktör analizi ile elde edilen alt boyutları ile toplam ölçek puanı arasındaki ilişki Pearson Momentler Çarpım korelasyonu ile birinci çalışma grubu üzerinden belirlenmiştir. Cohen ve Swerdlik (2002), ölçme aracının homojenliğini, tek boyutlu bir özelliği ne derece ölçebildiğini alt test puanları ile toplam puan arasındaki korelasyonunun verdiğini belirtmiştir (Akt., Atılgan, Kan ve Doğan, 2011). Alt boyut ve toplam ölçek puanı arasındaki korelasyon katsayıları Tablo 2'de verilmiştir.

Tablo 2. Alt Boyut ve Toplam Ölçek Puanı Arasındaki Korelasyon Katsayıları

\begin{tabular}{lccc}
\hline Kariyer & Aile Etkisi & Meslek Seçimi & Toplam Puan \\
\hline Kaygıs1 & - & $.386^{* *}$ & $.751^{* *}$ \\
Aile Etkisi & - & $.899^{* *}$ \\
Meslek Seçimi & & & - \\
Toplam Puan & & &
\end{tabular}

Tablo 2 incelendiğinde, ölçeğin alt boyutları arasındaki korelasyon katsayısının .386 $(\mathrm{p}<.001)$, aile etkisi ile toplam puan arasındaki korelasyonun .751 $(\mathrm{p}<.001)$, meslek seçimi alt boyutu ile toplam puan arasındaki korelasyonun $.899(\mathrm{p}<.001)$ olduğu ve tüm korelasyonlar arasında anlamlı ilişkilerin olduğu görülmektedir. Şencan (2005), elde edilen korelasyon katsayısını .20 ile .39 arasında düşük, .40 ile .59 arasında orta derecede, .60 ile .80 arasında güçlü ilişki olarak yorumlamıştır. Buna göre boyutlar arasındaki korelasyon düşüktür. Alt boyutlar ile toplam puan arasındaki korelasyonun yüksek olması ise iki boyutun aynı temel yapıyı ölçtüklerine işaret etmektedir.

\section{Doğrulayıcı faktör analizine ilişkin bulgular}

Açımlayıcı faktör analizi sonuçlarına göre ortaya çıkan yapının bir model olarak doğrulanıp doğrulanmadığını test etmek amacıyla ikinci çalışma grubu üzerinden 14 madde ile doğrulayıcı faktör analizi yapılmıştır.

Doğrulayıc1 faktör analizi sonucunda elde edilen uyum indeksleri; $\chi^{2} / \mathrm{sd}=2.518$, RMSEA $=0.067, \mathrm{CFI}=0.95, \mathrm{NFI}=0.92, \mathrm{NNFI}=0.94, \mathrm{SRMR}=0.055, \mathrm{GFI}=0.92$ ve $\mathrm{AGFI}=0.90$ 
bulunmuştur. Literatürde $\chi^{2} /$ sd değerinin büyük örneklemler için 3'ün altında olması mükemmel uyum, 5' in altında orta düzeyde uyum olarak nitelendirilmektedir (Akt., Çokluk, Şekercioğlu ve Büyüköztürk, 2010). Bu doğrultuda elde edilen $\chi^{2} /$ sd değerinin mükemmel düzeyde uyum verdiği söylenebilir. RMSEA değerinin .05'den küçük olması mükemmel, .08'den küçük olması iyi uyuma işaret etmektedir (Byrne ve Campbell, 1999; Jöreskog ve Sörbom, 1993). Modelden elde edilen RMSEA değerinin iyi uyuma sahip olduğu söylenebilir. CFI değerinin .95 ve üzerinde olması mükemmel uyumu, .90 ve üzerinde olması ise iyi uyumu göstermektedir (Hu ve Bentler, 1999). Elde edilen CFI değeri incelendiğinde mükemmel uyumun olduğu söylenebilir. NFI ve NNFI değerlerinin .90'nın üzerinde olması iyi uyumu göstermektedir (Bentler, 1980; Tabachnick ve Fidell, 2001). Bu doğrultuda NFI ve NNFI'ın iyi bir uyuma sahip olduğu görülmektedir. SRMR değerinin .08'den küçük olmas1 kabul edilir uyum olarak nitelendirilmektedir (Hu ve Bentler, 1999). Elde edilen SRMR değeri kabul edilebilir ölçütler içindedir. GFI ve AGFI değerlerinin 0.90 ve üzerinde olması iyi uyumu göstermektedir (Hooper, Coughlan ve Mullen, 2008). Bu açıdan modele ilişkin GFI ve AGFI değerlerinin iyi uyuma sahip olduğu görülmektedir. Sonuç olarak Kariyer Kaygısı ölçeği için elde edilen modele ait uyum indekslerinin kabul edilebilir uyum ölçütleri ile karşılaştırıldığında yeterli düzeyde olduğu tespit edilmiştir.

Ölçekte yer alan her bir maddeye ait gizil değişkenlerin gözlenen değişkenleri açıklama durumlarına ilişkin $t$ değerleri incelenmiştir. Kariyer kaygısı ölçeğine ait $t$ değerleri, aile etkisine yönelik kaygı için 8.17 ile 12.25 arasında, meslek seçimine yönelik kaygı için 4.38 ile 13.65 arasında değişmekte ve hesaplanan $\mathrm{t}$ değerleri tüm maddeler için $\mathrm{p}<.01$ düzeyinde anlamlıdır.

Kariyer kaygısı ölçeğine ilişkin DFA sonucunda elde edilen modele ait faktör yükleri Şekil 2'de verilmiştir. Şekil 2'de görüldüğü gibi kariyer kaygısı ölçeğinin maddelerine ilişkin faktör yükleri aile etkisine yönelik kaygı maddeleri için .59 ile .88, meslek seçimine yönelik kaygı maddeleri için .31 ile .86 arasında değişmektedir.

Sonuç olarak, DFA sonucunda elde edilen uyum indeksleri, her bir maddenin $t$ değeri ve maddelerin faktör yükleri incelendiğinde açımlayıcı faktör analizindeki yapının bir model olarak doğrulandığı söylenebilir.

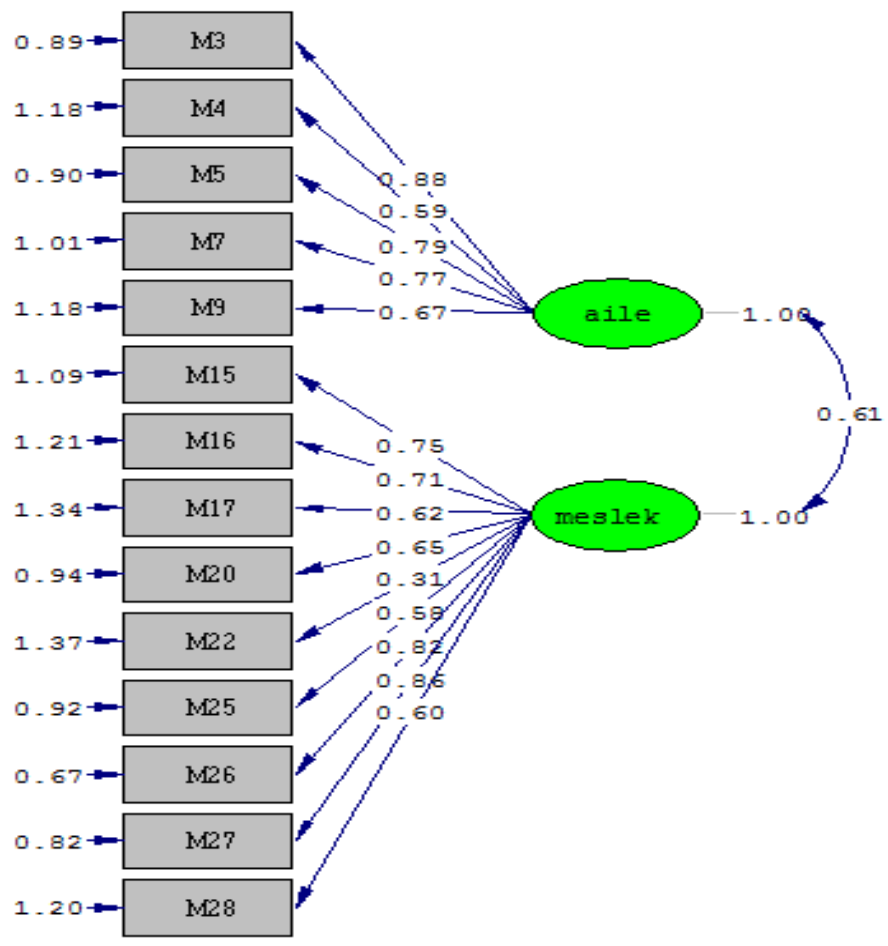

Şekil 2. Kariyer Kaygısı Ölçeği Faktör Yükleri 


\section{Güvenirliğe ilişkin bulgular}

Geliştirilen ölçme aracının güvenirliliği üçüncü çalışma grubu üzerinden Cronbach Alfa iç tutarlılık katsayısı ile belirlenmiştir. Yapılan analiz sonucunda kariyer kaygısı ölçeğinin kariyer gelişim sürecinde meslek seçimine yönelik kaygılarına ait güvenirlik .797, aile etkisine yönelik kaygılarına ait güvenirlik ise .742 bulunmuştur. Ölçme aracı için hesaplanan güvenirlik katsayısının .70 ve üzeri olması, ölçme aracından elde edilen puanların güvenirliği için yeterli görülmektedir (Büyüköztürk, 2007). Bu doğrultuda geliştirilen kariyer kaygısı ölçeğinin yeterli düzeyde güvenirliğe sahip olduğu söylenebilir.

Kariyer kaygısı ölçeğinin maddelerine ilişkin düzeltilmiş madde-toplam korelasyonları ve $\% 27$ 'lik alt-üst grup madde ortalama puanlart

Kariyer kaygısı ölçeğinde yer alan maddelerin ayırt ediciliğini belirlemek amacıyla üçüncü çalışma grubu üzerinden düzeltilmiş madde-toplam korelasyonu hesaplanmış, toplam puana göre \%27'lik alt ve üst grupların madde ortalama puanları arasındaki fark ilişkisiz t testi ile sınanmıştır. Elde edilen bulgular Tablo 3’te verilmiştir.

Tablo 3. Kariyer Kaygısı Ölçeğinin Maddelerine İlişkin Düzeltilmiş Madde-Toplam Korelasyonları ve \%27'lik Alt-Üst Grup Madde Ortalama Puanları t Testi Sonuçları

\begin{tabular}{|c|c|c|c|}
\hline $\begin{array}{l}\text { Kariyer } \\
\text { Kaygısı }\end{array}$ & Madde No & $\begin{array}{l}\text { Düzeltilmiş } \\
\text { Madde-Toplam } \\
\text { Korelasyonu }^{1}\end{array}$ & $\begin{array}{l}\text { t } \\
(\text { Alt \% 27- } \\
\text { Üst\%27) }\end{array}$ \\
\hline \multirow{6}{*}{ 吾 } & M3 & .588 & $16.541^{*}$ \\
\hline & M4 & .399 & $11.753^{*}$ \\
\hline & M5 & .565 & $16.150^{*}$ \\
\hline & M7 & .521 & $17.843^{*}$ \\
\hline & M9 & .458 & $13.278^{*}$ \\
\hline & M15 & .532 & $17.653^{*}$ \\
\hline \multirow{8}{*}{ 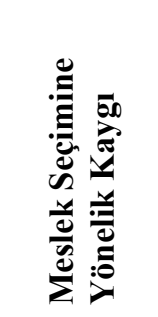 } & M16 & .541 & $19.421^{*}$ \\
\hline & M17 & .481 & $14.677^{*}$ \\
\hline & M20 & .458 & $13.764^{*}$ \\
\hline & M22 & .313 & $8.680^{*}$ \\
\hline & M25 & .465 & $14.587^{*}$ \\
\hline & M26 & .555 & $17.356^{*}$ \\
\hline & M27 & .577 & $18.311^{*}$ \\
\hline & M28 & .456 & $14.709^{*}$ \\
\hline
\end{tabular}

Tablo 3 incelendiğinde, ölçekte yer alan maddeler için hesaplanan düzeltilmiş maddetoplam korelasyonlarının aile etkisine yönelik kaygı boyutunda .399 ile .588 , meslek seçimine yönelik kaygı boyutunda ise .313 ile .577 arasında değiştiği görülmektedir. Madde-toplam korelasyonunun pozitif ve yüksek olması maddelerin benzer yapıyı ölçtüğü, iç tutarlılı̆̆ın yüksek olduğunu, ölçülmek istenen özelliği ölçmede amacına hizmet ettiğini gösterir (Büyüköztürk, 2007). Madde-toplam korelasyonu .30 ve daha yüksek olan maddelerin ölçülen özellik bakımından bireyleri iyi derecede ayırt ettiği, madde-toplam korelasyonu 0.20'nin altında olan maddelerin ise ölçekten çıkartılması gerektiği kabul edilmektedir (Büyüköztürk, 2007; Tavşancıl, 2006). Ölçekte yer alan maddelerin madde-toplam korelasyonlarının yanında $\% 27$ alt ve üst grupların madde ortalama puanları arasındaki farkta incelenmiş ve maddelerin ortalama puanlarına ilişkin $\mathrm{t}$ değerleri anlamlı $(\mathrm{p}<.001)$ bulunmuştur. Bu doğrultuda ölçekte yer alan maddelerin kariyer kaygısını ölçmeye yönelik olduğu, maddelerin öğrencileri kariyer kaygısı bakımından ayırt ettiği söylenebilir.

\section{Sonuç, Tartışma ve Öneriler}

$\mathrm{Bu}$ çalışmada, lise öğrencilerinin kariyer kaygılarını belirlemede kullanılabilecek geçerli ve güvenilir bir ölçme aracının geliştirilmesi amaçlanmıştır. Geliştirilen Kariyer Kaygısı Ölçeği, beşli likert tipinde bir ölçek olup, aile etkisinden kaynaklı kaygılar ve meslek seçimine yönelik 
kaygılar olmak üzere iki alt boyuttan oluşmaktadır. Ölçeğin aile etkisinden kaynaklı kaygılar boyutu beş maddeden oluşmakta ve bireylerin kariyer gelişim süreçlerinde verecekleri okul seçimi, meslek seçimi gibi konularda ailesinin etkisine bağlı olarak yaşadığı kaygıları içermektedir. Literatürde ergenlerin kariyer gelişim süreçleri ve aile arasındaki ilişkiye vurgu yapan çalışmalar bulunmaktadır (Ginevra, Nota ve Ferrari, 2015; Liu, McMahon, and Watson, 2015; Vignoli vd., 2005; Vignoli, 2015). Meslek seçimine yönelik kaygılar boyutunda ise dokuz madde bulunmaktadır. Bireyin meslek seçimine ilişkin kaygıları ise bireyin gelecekte seçmeyi düşündüğü mesleğe yönelik genel kaygıları içermektedir.

Ölçeğin geliştirilme sürecinde farklı çalışma gruplarından elde edilen verilerle açımlayıcı ve doğrulayıcı faktör analizi yapılmıştır. AFA sonucunda toplam varyansın \%44.4'ünü açıklayan 14 maddeden ve iki boyuttan oluşan bir yapı elde edilmiştir. Geliştirilen ölçeğe ilişkin model DFA ile sınanmıştır. DFA sonucunda elde edilen uyum indeksleri kabul edilebilir sınırlar içinde bulunmuş, kariyer kaygısı ölçeğinin iki boyutlu yapısı bir model olarak doğrulanmıştır. Ölçeğin güvenirliği Cronbach alfa iç tutarlık katsayısıyla incelenmiştir. Ölçeğin meslek seçimine yönelik kaygılarına ait güvenirlik .797, aile etkisine yönelik kaygılarına ait güvenirlik ise .742 bulunmuştur. Madde geçerliğine kanıt olması açısından madde-toplam korelasyonu hesaplanmış, \%27'lik alt ve üst grup madde ortalamaları arasındaki fark t testi ile incelenmiştir. Ölçekte yer alan maddelerin kariyer kaygısını ölçmeye yönelik olduğu, maddelerin öğrencileri kariyer kaygısı bakımından ayırt ettiği tespit edilmiştir. Yapılan tüm analizler 1şı̆̆ında ise lise öğrencilerine yönelik geliştirilen kariyer kaygısı ölçeğinin kullanılabilecek düzeyde geçerli ve güvenilir olduğu, ölçülmek istenen özellik bakımından bu özelliğe sahip olan bireylerle olmayan bireyleri ayırabildiği sonucuna ulaşılmıştır.

Uygulama ve analizler sonrasında Kariyer Kaygısı Ölçeği'nin 14 maddeden oluştuğu ve kariyer gelişim sürecinde aile etkisinden kaynaklı (5) ve kariyer gelişim sürecinde meslek seçimine yönelik kaygı (9) olmak üzere iki boyutlu bir yapıya sahip olduğu belirlenmiştir. Beşli Likert tipinde olan ölçek "hiç katılmıyorum (1)", "katılmıyorum (2)", "kararsızım (3)", "katılıyorum (4)" ve "tamamen katılıyorum (5)" şeklinde yanıtlanmaktadır. Ölçeğin alt boyutlarından alınan yüksek puan ilgili boyuta yönelik yaşanan kariyer kaygısının yüksek olduğuna işaret etmektedir.

Bu çalışmada bir mesleğe yönelme, bir mesleği seçme aşamasında bulunan lise öğrencilerinin kariyer kaygılarını belirlemeye dönük bir ölçek geliştirilmiştir. Literatürde lise öğrencilerinin kariyer kaygılarını belirlemek amacıyla Mallet ve Vignoli (2005) tarafindan geliştirilen “Gelecek Okul ve Kariyer Kaygısı" ölçeği bulunmakla birlikte, Türkiye'de bu konuda kullanılan bir ölçme aracına rastlanmamıştır. Bu açıdan geliştirilen bu ölçeğin lise öğrencilerinin kariyer kaygılarının tespit edilip, meslek seçme, mesleğe yönlendirme vb. durumlarda rehberlik yapmak amaçlı önemli katkı sağlayacağ 1 düşünülmektedir. Bununla birlikte çalışmanın Nevşehir İli merkez ilçesinde bulunan lise öğrencileri ile yapılmış olması bir sınırlılık olarak görülmektedir. Daha sonraki çalışmalarda farklı örneklem gruplarında ölçeğin geçerliği ve güvenirliği yeniden araştırılabilir. Üniversite öğrencilerinin kariyer kaygılarını ortaya koymak amaçlı başka bir ölçek geliştirilebilir.

\section{Kaynaklar}

Akgün, F. ve Özgür, H. (2014). Examination of the anxiety levels and attitudes of the information technology pre service teachers towards the teaching profession. Journal of Theory and Practice in Education, 10(5), 1206-1223.

Alkan, N. (2014). Üniversite adaylarının bölüm tercihleri: Bir kariyer araştırma yöntemi olarak bölüm tanıtımları. Türk Psikolojik Danışma ve Rehberlik Dergisi, 5(41), 61-74.

Atılgan, H., Kan, A. ve Doğan, N. (2011). Eğitimde ölçme ve değerlendirme. Ankara: Anı Yayıncilik.

Bacanlı, F., Eşici, H. ve Özünlü, M.B. (2013). Kariyer karar verme güçlüklerinin çeşitli değişkenlere göre incelenmesi. Türk Psikolojik Danışma ve Rehberlik Dergisi, 5(40), 198-211. 
Bentler, P.M. (1980). Multivariate analysis with latent variables: Causal modeling. Annual Review of Psychology, 31, 419-456.

Brown, C. (1997). Sex differences in the career development of urban African American adolescents. Journal of Career Development, 23(4), 295-304.

Bryman, A., \& Cramer, D. (2001). Quantitative data analysis with SPSS release 10 for windows. London: Routledge.

Byrne, B., \& Campbell, T. L. (1999). Cross-cultural comparisons and the presumption of equivalent measurement and theoretical structure: A look beneath the surface. Journal of Cross-Cultural Psychology, 30(5), 555-574.

Büyükgöze-Kavas, A. (2012). Kariyer karar ölçeği'nin türkçe uyarlaması: Geçerlik ve güvenirlik çalışması. Türk Psikolojik Danışma ve Rehberlik Dergisi, 4(38), 159-168.

Büyüköztürk, Ş. (2007). Sosyal bilimler için veri analizi el kitabı. Ankara: Pegem Akademi Yayıncilik.

Cabı, E. ve Yalçınalp, S. (2013).Öğretmen adaylarına yönelik mesleki kaygı ölçeği: Geçerlik ve güvenirlik çalışması. Hacettepe Üniversitesi Eğitim Fakültesi Dergisi, 44: 85-96.

Campagna, C.G., \& Curtis, G.J. (2007). So worried I don't know what to be: Anxiety is associated with increased career indecision and reduced career certainty. Australian Journal of Guidance and Counseling, 17, 91-96.

Ceyhan, E. ve Gürcan-Namlu, A.G. (2000). Bilgisayar kaygısı ölçeği: Geçerlik ve güvenirlik çalışması. Anadolu Üniversitesi Eğitim Fakültesi Dergisi, 10(2), 77-93.

Child, D. (2006). The essentials of factor analysis. Continuum, London.

Comrey, A.L., \& Lee, H.B. (1992). A first course in factor analysis. Hillsdale, NJ: Erlbaum.

Corkin, D., Arbona, C., Coleman, N., \& Ramirez, R. (2008). Dimensions of career indecision among Puerto Rican college students. Journal of College Students Development, 49, 8194.

Çokluk, Ö., Şekercioğlu, G. ve Büyüköztürk, Ş. (2010). Sosyal bilimler için çok değişkenli istatistik: SPSS ve LISREL uygulamaları. Ankara: Pegem Akademi Yayıncılık.

Daniels, L.M., Stewart, T. L., Stupnisky, R.H., Perry, R.P., \& LoVerso, T. (2011). Relieving career anxiety and indecision: The role of undergraduate students' perceived control and faculty affiliations. Soc Psychol Educ., 14, 409-426.

Doğan, T. (2010).Sosyal görünüş kaygısı ölçeği'nin Türkçe uyarlaması: Geçerlik ve güvenirlik çalışmasi. Hacettepe Üniversitesi Ĕ̆itim Fakültesi Dergisi, 39, 151-159.

Erdoğmuş Zorver, C. ve Korkut Owen, F. (2014).Kariyer Uyumu ve İyimserliği Ölçeği'nin geliştirilmesi. International Journal of Human Sciences, 11(2), 314-331.

Ergür-Oktar, D. (2004). Yabancı dil öğrenimi sürecinde kayg1. Hacettepe Üniversitesi Eğitim Fakültesi Dergisi, 26, 48-53.

Erkuş, A. (2012). Psikolojide ölçme ve ölçek geliştirme I: Temel kavramlar ve işlemler. Ankara: Pegem Akademi.

Ginevra, M.C., Nota, L., \& Ferrari, L. (2015). Parental support in adolescents' career development: Parents' and children's perceptions. The Career Development Quarterly, 63, 2-15.

Gottfredson, L. S. (2002). Gottfredson's theory of circumscription, compromise, and selfcreation. In. D. Brown (Eds.), Career Choice and Development (pp. 85-148). New York: Wiley.

Fuqua, D.R., Newman, J. L., \& Seaworth, T.B. (1988). Relation of state and trait anxiety to different components of career indecision. Journal of Counseling Psychology, 35(2), 154-158.

Fuqua, D.R., Seaworth, T.B., \& Newman, J.L. (1987). The relationship of career indecision and anxiety: A multivariate examination. Journal of vocational behavior, 30, 175-186.

Hardin, E.E., Varghese, F.P., Tran, U.V., \& Carlson, A.Z. (2006). Anxiety and career exploration: Gender diferences in the role of self-construal. Journal of Vocational Behavior, 69, 346-358. 
Hartung, P.J., Porfeli, E.J., \& Vondracek, F.W. (2005). Child vocational development: A review and reconsideration. Journal of Vocational Behavior, 66, 385-419.

Hawkins, J.G., Bradley, R.W., \& White, G.W. (1977). Anxiety and the process of deciding about a major and a vocation. Journal of Counseling Psychology, 24, 398-403.

Herr, E.L., \& Cramer, S.H. (1992). Career guidance and counseling through the lifespan: Systematic approaches. New York, NY: HarperCollins.

Hooper, D., Coughlan, J., \& Mullen, M.R. (2008). Structural equation modelling: guidelines for determining model fit. The Electronic Journal of Business Research Methods, 6(1), 5360.

Hartman, B.W., Fuqua, D.R., \& Blum, C.R. (1985). A path-analytic model of career indecision. The Vocational Guidance Quarterly, 33, 231-240.

Hu, L., \& Bentler, P.M. (1999). Cutoff criteria for fit indexes in covariance structure analysis: conventional criteria versus new alternatives. Structural Equation Modeling, 6(1), 1-55.

Iş1k, E. (2012). The relationship of career decision self-efficacy, trait anxiety, and affectivity among undergraduate students. Psychological Reports, 111, 805-813.

Işık, E. (2014). Çocuk kariyer gelişimi ile yaşam doyumu ve durumluk kaygı arasındaki ilişkilerin incelenmesi. Illköğretim Online, 13(2), 682-693.

Jöreskog, K. G., \& Sörbom, D. (1993). LISREL 8: structural equation modeling with the simplis command language. Lincolnwood: Scientific Software International, Inc.

Jöreskog, K. G., \& Sörbom, D. (2004). LISREL 8.7 for Windows [Computer Software]. Lincolnwood, IL: Scientific Software International, Inc.

Kalafat, T. (2012). Kariyer geleceği ölçeği (KARGEL): Türk örneklemi için psikometrik özelliklerinin incelenmesi. Türk Psikolojik Danışma ve Rehberlik Dergisi, 4 (38), 169179.

Kanten, S. (2012). Kariyer uyum yetenekleri ölçeği: Geçerlik ve güvenilirlik çalışması. Süleyman Demirel Üniversitesi Sosyal Bilimler Enstitüsü Dergisi, 16, 191-205.

Köklü, N., (1996). Statistical anxiety scale, psychometric data. Education and Science, 20(102), 45-49.

Köse, S. (2006). Müzik öğretmeni adaylarının mesleki kaygıları. Mehmet Akif Ersoy Üniversitesi Ĕ̈itim Fakültesi Dergisi, Sayı 12, 80-89.

Kuzgun, Y. (2011). Rehberlik ve psikolojik danışma. Nobel:Ankara.

Liu, J., McMahon, M., \& Watson, M. (2015) Parental influence on mainland Chinese children's career aspirations: child and parental perspectives. International Journal for Educational and Vocational Guidance, 15 2: 131-143. doi:10.1007/s10775-015-9291-9

Melanlığlu, D. (2014). Okuma kaygısı ölçeğinin psikometrik özelliklerinin belirlenmesi. Eğitim ve Bilim, 39, 176.

Mojgan, F.H., Kadir, R.A., \& Soheil, S. (2011). The relationship between state and trait anxiety and career indecision of undergraduatestudents. International Education Studies, 3, 31135.

Muro, J.J., \& Kottman, T. (1995). Guidance and counseling in the elemantary and middle schools- A practical approach. Brown Benchmark Publishers.

O'Hare, M.M., \& Tamburri, E. (1986). Coping as moderator of a moderator of the relation between anxiety and career decision making. Journal of Counseling Psychology, 33, 255- 264.

Öner, N. ve Le Compte, A. (1983). Durumluk-sürekli kaygl envanteri el kitabı. Boğaziçi Üniversitesi Matbaas1, 1 Bask1, İstanbul.

Özbay, Y. ve Palancı, M. (2001). Sosyal kaygı ölçeği: Geçerlik güvenirlik çalışması. VI Ulusal Psikolojik Danışma ve Rehberlik Kongresi, Ankara, ODTÜ.

Öztemel, K. (2014). Duygusal ve kişilik ilişkili kariyer karar verme güçlükleri ölçeği'nin kısa formu. Türk Psikolojik Danışma ve Rehberlik Dergisi, 5(42), 244-255.

Özyürek, R. (2013). Kariyer psikolojik danışmanlı̆̆ kuramları: Çocuk ve ergenler için kariyer rehberliği uygulamaları. Nobel Yayınevi:Ankara. 
Özdemir Yaylacı, G. (2007). İlköğretim düzeyinde kariyer eğitimi ve danışmanlığı. Bilig, 40, 119-140.

Öztürk, E. (2013). Öğretmen adaylarının bilgisayar kaygısı ve bilgisayar özyeterliliklerinin çeitli değişkenler açısından incelenmesi. Hacettepe Üniversitesi Eğitim Fakültesi Dergisi, 44: 275-286.

Patton, W., \& McMahon, M. (2014). Career development and systems theory: Connecting theory and practice. Sense Publishers: Rotterdam

Peng, H. (2005). Reduction in state anxiety scores of freshmen through a course in career decision. International Journal for Educational and Vocational Guidance, 5: 293-302.

Pett, M., Lackey, N. \& Sullivan, J. (2003). Making sense of factor analysis. Thousand Oaks: Sage Publications, Inc.

Rowland, K.D. (2004). Career decision-making skills of high school students in the Bahamas. Journal of Career Development, 31(1), 1-13.

Ritter, E., Strauser, D.R., O'Sullivan, D., Reid, J., Khosravisnasr, S., \& Cronin, T. (2014). Theories of career development and work adjustment, (in. Career development, employment and disability in rehabilitation: From theory to practice.) Eds: (David. R. Strauser) (Pp.97-113) Springer Publisher Company: New York.

Saban, A., Korkmaz, İ. ve Akbaşlı, S. (2004). Öğretmen adaylarının mesleki kaygıları. Eğitim Araştırmaları Dergisi, 5(17), 198-209.

Spielberger, C. D., (1972). Anxiety: Current trends in theory and research. New York: Academic Press Inc.

SPSS 15 (2006). SPSS 15.0 for Windows. Chicago (IL): SPSS Inc

Super, D.E. (1990). A life span, life space approach to career development. D. Brown \& L. Brooks (Ed.) içinde, Career choice and development: Applying contemporary theories to practice (2. ed., ss. 197-261). San Fransico: Jossey-Bass.

Strongman, K.T. (1995). Theories of anxiety. New Zealand Journal of Psychology, 24,2,4-10.

Şencan, H. (2005). Sosyal ve davranışsal ölçümlerde güvenilirlik ve geçerlilik. Ankara: Seçkin Yayınları.

Tabachnick, B.G., \& Fidell, L.S. (2001). Using multivariate statistics. New York: Allyn $\&$ Bacon Inc.

Tavşancıl, E. (2006). Tutumların ölçülmesi ve SPSS ile veri analizi. Ankara: Nobel Yayın Dağıtım Ltd. Şti.

Ulu, E. (2007). Lise öğrencilerinin kariyer inançlarının bazı değişkenlere göre yordanması. Yayımlanmamış yüksek lisans tezi. Ege Üniversitesi, Sosyal Bilimler Enstitüsü, İzmir.

Ünaldı, Ü.E. ve Alaz, A. (2008). Coğrafya öğretmenliğinde okuyan öğretmen adaylarının mesleki kaygı düzeylerinin çeşitli değişkenler açısından incelenmesi. Selçuk Üniversitesi Eğitim Fakültesi Dergisi, 26, 1-13.

Ünsal, P. (2014). Kariyer gelişim kuramları ve kariyer danışmanlığ , Nobel: Ankara

Varol, S. (1990). Lise son sınıf ögrencilerinin kaygılarını etkileyen etmenler. Yayımlanmamış yüksek lisans tezi. Ondokuz Mayıs Üniversitesi, Sosyal Bilimler Enstitüsü, Samsun.

Vignoli, E. (2015). Career indecision and career exploration among older French dolescents: the specific role of general trait anxiety and future school and career anxiety. Journal of Vocational Behavior, doi: 10.1016/j.jvb.2015.06.005.

Vignoli, E., Croity-Belz, S., Chapeland, V., Fillipis, A., \& Garcia, M. (2005). Career exploration in adolescents: The role of anxiety, attachment and parenting style. Journal of Vocational Behavior, 67(153-168).

\section{Extended Abstract \\ Introduction}

Career development is a life long, complex and multidimensional process that commence during childhood years (Gottfredson, 2002; Hartung, Porfeli \& Vondracek, 2005; Herr \& Cramer, 1992; Super, 1990). According to Super, career exploration and decision-making play a central role throughout adolescence (Brown, 1997). 
In Turkey, decisions regarding the choice of profession are virtually irreversible. In line with career counseling practices and regulations, students are required to choose at least their intended types of high schools after grade eight or nine. According to central entrance examination, once placed in a university program, students must re-sit this test if they wish to enroll in another program (Özyürek, 2013). Irreversibility of decisions made barely at a phase of making aspirations and formulating ideals about one's professional future also stimulate negative emotions among students. Anxiety is one of the factors affecting students' career development, as Vignoli, Croity-Belz, Chapeland, Fillipis and Garcia stated (2005). Mallet and Vignoli (2005) defined the following three different forms of career trait anxiety; fear of feeling in one's academic or professional career, fear that one's parent might be disappointed in one's career choice and fear of moving away from family and intimate relationships as a consequence of occupational or academic requirements (Cited: Vignoli et al., 2005; Vignoli, 2015).

Literature review on anxiety in scope of career development process shows that studies particularly focus on the relation between career indecision and anxiety (Campagna, \& Curtis, 2007; Daniels, Stewart, Stupnisky, Perry, \& LoVerso, 2011; Fuqua, Newman, \& Seaworth; 1988; Fuqua, Seaworth \& Newman, 1987; Hawkins, Bradley \& White, 1977; Peng, 2005).

Literature review did not render any result of former studies carried out in Turkey on career anxiety during adolescence. On the other hand, there are a limited number of studies on anxiety and career development (Işık, 2012; Işık; 2014). Literature review indicates that the researchers determine the career anxiety ratings in scope of their research on career vs. anxiety by means of Future School and Career Anxiety scale developed by Vignoli et al., (2005) and Vignoli, (2015).

Literature review did not render any result of former studies carried out in Turkey on anxiety ratings in scope of career development, neither has a scale developed to rate career anxiety during adolescence been found in Turkish literature. It is believed that a scale to be developed in this field will make crucial contributions to the literature.

\section{Method}

\section{Research Sample and Activities}

The study was conducted during the 2014-2015 academic year on three different groups, the first of which was comprised of 350 grade 11 and 12 students from 6 different high schools located in Nevşehir city center, the second 337 and the third 687 students, respectively.

\section{Development of the scale}

In the development of scale, initially literature review on anxiety, career development and career anxiety was carried out. A group of students, resembling the target group, were asked to write essays on the subject. Questions addressed to students on the subject are concerned with anxiety on such topics as their family and education system-based concerns/anxiety over career development/choice/plans, their general anxiety over career development and anxiety on tendency towards a profession, receiving education in the relevant field and finding a job, respectively.

The scale was presented to a total of six experts in the field for their opinion, according to which the items in the scale were reviewed. In the scale development process, exploratory and confirmatory factor analysis was performed. Furthermore, in order to verify item validity, item-total score correlation of each item was calculated and unrelated samples t-test was run on $\% 27$ sub and super-group items mean scores. SPSS 15 and LISREL 8.7 software were utilized in the analysis of the data.

\section{Findings}

KMO value derived from exploratory factor analysis on the first group was found to be 0.856 . Principal components analysis was performed as a factorization technique and exploratory factor analysis by means of direct oblimin as a conversion technique. 
The primary factor of the scale, developed to rate career anxiety of high school students by taking items and conceptual structure into consideration according to AFA results, was called anxiety on choice of profession and the secondary factor dubbed anxiety on the family effect.

The career choice aspect of the scale consists 9 items and explains \%25.06 of total variance. Factor load of the items under career choice category of the scale ranges from .721 to .48. Meanwhile, there are 5 items regarding the family effect, which explain $\% 19.34$ of total variance and the factor load of items under this category varies between .794 and .562 . The total variance explained by the entire scale is \%44.4.

Fit indices, derived from confirmatory factor analysis implemented in order to verify whether the model structure is plausible or not as a result of exploratory factor analysis, were found to be $\chi^{2} / \mathrm{sd}=2.518$, RMSEA $=0.067, \mathrm{CFI}=0.95$, NFI=0.92, NNFI=0.94, SRMR=0.055, GFI $=0.92$ and $\mathrm{AGFI}=0.90$.

Consequently, one may assert upon assessment of fit indices derived from DFA, t-test values of each item and the factor loads of the items that the structure analyzed by exploratory factor analysis is a model fit.

As a result of analysis, reliability rate of anxiety over choice of profession was found to be .797 and that of family effect .742 in scope of career development. Modified item-total correlation was calculated for scale items, accordingly the figures range from .399 to .588 in family effect aspect and .313 to .577 in anxiety over profession choice aspect, respectively. Difference among \%27 sub and super-group items mean was evaluated and the t-test values of the mean scores of the items were found to be significant meaningful $(\mathrm{p}<0.001)$.

\section{Conclusions, Discussion and Suggestions}

The purpose of this study is to develop a valid and reliable assessment tool to rate career anxiety of high school students. The items in the scale were detected to be applicable to rate career anxiety and to differentiate students in terms of career anxiety level. In light of all analyses, the career anxiety scale for high school students was found to be reasonably valid and reliable and that the scale is capable of differentiating the individuals with the targeted properties from those without them.

Although literature review shows the existence of "Future School and Career Anxiety" scale developed by Mallet and Vignoli (2005) in order to detect anxiety ratings of high school students, no assessment tool in this field was found to be available in Turkey. In this regard, the scale developed by the researcher is believed to make considerable contribution to determine career anxiety of high school students, thus offer counseling for career choices and professional orientation etc. Besides, the fact that the study was carried out on high school students resident in Nevşehir city center is considered to be a limitation. In future studies, validity and reliability of the scale may be reassessed through implementation on different samples, likewise scales for university students may be developed in order to rate their career anxiety. 